\title{
Morphometric Correlations of the Voice Category (VC) in Professional Singers with Oropharyngeal and Laryngeal Anatomy Using Stroboscopy and Cervical Posteroanterior Radiography
}

\author{
Athina Zarachi' ${ }^{1}$ ( ), Dionysios Tafiadis ${ }^{2,3}$, Nafsika Ziavra ${ }^{2}$, Ioannis Kastanioudakis ${ }^{1}$, \\ Efthymis Dimakis ${ }^{4}$, Angelos Liontos ${ }^{5}{ }^{(0)}$, Maria Argyropoulou ${ }^{6}$, Georgios Exarchakos ${ }^{1}$ \\ ${ }^{1}$ Department of Otorhinolaryngology, Head and Neck Surgery, Faculty of Medicine, School of Health Sciences, University of \\ Ioannina, Ioannina, Greece \\ ${ }^{2}$ Department of Speech \& Language Therapy, School of Health Sciences, University of Ioannina, Ioannina, Greece \\ ${ }^{3}$ Department of Health Sciences, Speech and Language Therapy, European University Cyprus, Nicosia, Cyprus \\ ${ }^{4}$ Division of Biostatistics and Epidemiology, Department of Medical School, University of Ioannina, Ioannina, Greece \\ ${ }^{5}$ Faculty of Medicine, Department of Internal Medicine, School of Health Sciences, University of Ioannina, Ioannina, Greece \\ ${ }^{6}$ Faculty of Medicine, Department of Radiology, School of Health Sciences, University of Ioannina, Ioannina, Greece \\ Email: athinazarachi@gmail.com, ikastan@uoi.gr, exarchakos.george@gmail.com, tafiadis@uoi.gr, tafiadis@uoi.gr, \\ nziavra@uoi.gr,efdimakis@gmail.com,angelosliontos@gmail.com,margyrop@uoi.gr
}

How to cite this paper: Zarachi, A., Tafiadis, D., Ziavra, N., Kastanioudakis, I., Dimakis, E., Liontos, A., Argyropoulou, M. and Exarchakos, G. (2021) Morphometric Correlations of the Voice Category (VC) in Professional Singers with Oropharyngeal and Laryngeal Anatomy Using Stroboscopy and Cervical Posteroanterior Radiography. International Journal of Otolaryngology and Head \& Neck Surgery, 10, 277-299. https://doi.org/10.4236/ijohns.2021.104026

Received: May 20, 2021

Accepted: July 9, 2021

Published: July 12, 2021

\begin{abstract}
Objective(s): The aim of this study is to explore if there is a correlation between the typical voice classification and the oropharyngeal and laryngeal morphology, using video laryngeal stroboscopy and cervical posterior-anterior radiography on professional singers in Greece. Methods: 55 professional singers (28 females: 7 sopranos, 12 mezzo-sopranos, and 9 contraltos; 27 males: 8 tenors, 12 baritones and 7 basses) were recruited for this study. All participants underwent stroboscopic and cervical posterior-anterior radiographic imaging of their oral pharyngeal and laryngeal area. Additionally, the voice classification and features (e.g., height, weight) of individuals were correlated statistically. Results: Statistically significant correlations were observed between the VC of the participants with the Phonetic Area (PA) $(r=$ $-0.451, \mathrm{p}=0.001)$ and the VC with the Oral-pharyngeal Cavity $(\mathrm{OPC})$ area $(\mathrm{r}$ $=-0.402, \mathrm{p}=0.001)$ in the total sample. Specifically, in male singers, the PA and VC correlation was $\mathrm{r}=-0.319, \mathrm{p}=0.047$, and the VC and OPC area was $\mathrm{r}=-0.328, \mathrm{p}=0.044$. Likewise, in female singers, the PA area and VC and PA were $\mathrm{r}=-0.336, \mathrm{p}=0.041$ and the OPC area and VC were $\mathrm{r}=-0.344, \mathrm{p}=$
\end{abstract}


Copyright (C) 2021 by author(s) and Scientific Research Publishing Inc. This work is licensed under the Creative Commons Attribution International License (CC BY 4.0).

http://creativecommons.org/licenses/by/4.0/
0.039. The analysis confirmed no correlations between VC and height and body weight. Conclusions: The cervical posteroanterior radiography in conjunction with laryngeal stroboscopy provided new morphometric correlations of the VC of professional singers with their Oropharyngeal and Laryngeal Anatomy.

\section{Keywords}

Laryngeal Anatomy, Professional Singers, Cervical Posteroanterior Radiography, Stroboscopy, Voice Classification

\section{Introduction}

The larynx has many functions, such as airway protection in swallowing and the maintenance of homeostasis in respiration and phonation. These functional properties are based on the special anatomical structures of the larynx [1] [2] [3] [4]. The larynx, as well as the lung and the vocal tract system represent the oldest and commonest "musical instrument": it houses the vocal folds, and produces sound as well as the acoustic characteristics of the voice, such as pitch and volume [4] [5]. It can be affected by numerous factors, including hormonal changes, age, sex, body type, the size of anatomical structures, the length of vocal folds or psychological conditions [4] [6] [7] [8].

The main area involved in vocalization is the vocal tract, which extends from the superior surface of the vocal folds to the lips [1]. The vocal track is separated anatomically into three main areas: 1 ) the nasopharynx (leading from the skull base to the soft palate), 2) the oropharynx (from the soft palate to the glosso-epiglottic folds) and 3) the laryngopharynx (from the glosso-epiglottic folds to the lower border of the cricoid cartilages) [1].

Singing is considered a type of human expression [9] [10] [11] and a complicated procedure that can be influenced by physical, psychological, environmental social and cultural factors [9] [12] [13] [14] [15]. Several researchers have attempted to quantify the factors that influence and constitute this phenomenon, as well as the morphometric and physiological characteristics of the larynx, while singing takes place [16]-[22].

Most of the studies correlate the classical singing range with body type, claiming that low-tone voices (bass) tend to correlate with taller people, while high-tone voices (tenor and soprano) correlate with shorter people [23]. Furthermore, many studies have suggested that there is a relationship between laryngeal size (length, shape and thickness of the vocal folds) and qualitative vocal characteristics (pitch, loudness and timbre), as they are observed clinically and through correlations, using special imaging techniques [15] [23] [24] [25] [26].

Specifically, in 1938, Zimmermann measured the length of the vocal folds in men and women using Exner's laryngometer [27] [28]. He concluded that male 
voices can be classified into three basic categories: bass $(24-25 \mathrm{~mm}$, vocal folds length range), baritone (21 - $27 \mathrm{~mm}$ ), and tenor (18 - $20 \mathrm{~mm})$. He also classified female voices into contralto (18 - $21 \mathrm{~mm})$, mezzosoprano (18 - $21 \mathrm{~mm})$, and soprano $(14-17 \mathrm{~mm})$ [27] [28]. The above classification was later confirmed in Neng \& Siao's study using radiological techniques [27] [28] [29].

Usually, a vocal coach will classify a student's voice based on his/her personal judgment [30]. They will take into consideration some quality of the voice, such as pitch, loudness and timbre, as well as "passagio", which refers to the transition points of the singing voice [31] [32]. Although this is an initial classification procedure used in conservatories, research efforts using objective methods have nevertheless confirmed it as fit for purpose [31]-[38].

In contrast, ENT doctors use objective assessments that provide information on the anatomy of the vocal system and the physiology and function of voicing [39] [40] [41]. Furthermore, when determining the voice category of a professional or amateur singer, the ENT physician will take information on the morphometric characteristics of the voice into account [42] [43] [44].

The classification of a singing voice depends on several parameters [42]-[48]. Of these, the major parameter is the determination of vocal tone and its range during singing, for both males and females. This usually reaches two octaves, rarely extending to three or more [29] [49] [50]. In accordance with the above, male and female singers have been categorised into the following groups: soprano, mezzosoprano, contralto, tenor, baritone and bass [27] [28] [51].

Exarchakos [28] suggested that the measurements of the distances between the anatomical structures involved in the procedure of singing (from the cervical incisor to the medulla of the hard palate (CI-MHP), from the medulla of the hard palate to the second cervical vertebra (MHP-SCV) and finally the distance from the second cervical vertebra to the anterior incision (SCV-AI)) can assist in distinguishing singers into specific vocal groups (Figure 1). This can be accomplished via the comparison of the differences between the distances of the vocal tract [52].

In the literature, several correlations to classic voice range classification have been suggested, taking into consideration parameters such as body mass, height and laryngeal morphology [23] [52] [53]. All these correlations were performed using a variety of methods, such as video laryngeal endoscopy [54], stroboscopy [55], radiographic imaging], or even ultrasound imaging [25] [26] [56] [57] [58] [59] [60].

Considering the above, the purpose of this study is to provide evidence, using stroboscopy and cervical posteroanterior radiography, that there is a good correlation between the voice classification of professional singers and their oral pharyngeal and laryngeal anatomy. Due to the fact that there has never been a similar study in the past, the results of this research will advance the existing research in such a way that we can probably talk about a new classification of the voice category. 


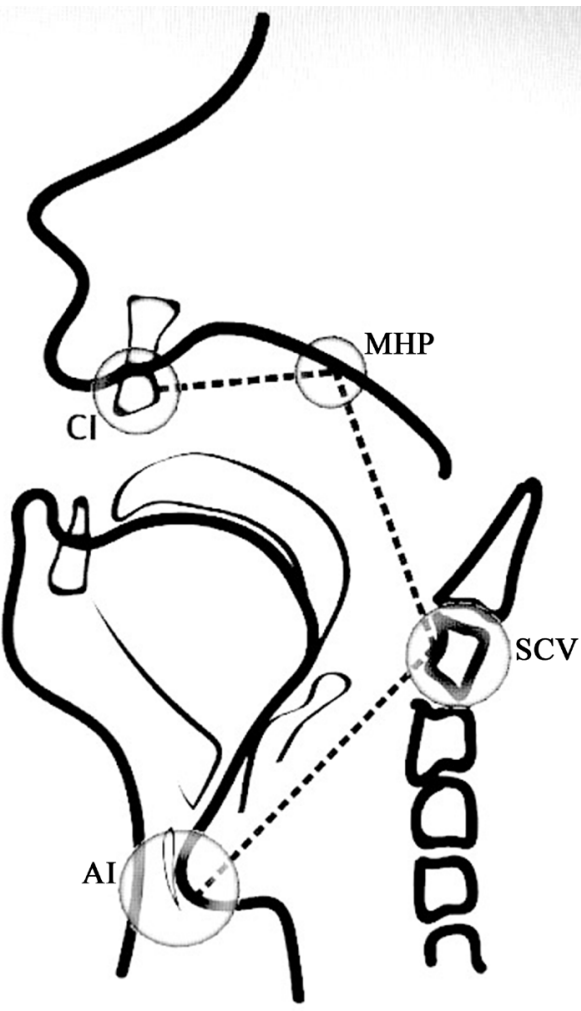

$\mathrm{CI}=$ Cervical Incisor, $\mathrm{MHP}=$ Medulla of the Hard Palate, $\mathrm{SCV}=$ Second Cervical Vertebra, $\mathrm{AI}=$ Anterior Incision

Figure 1. Anatomical parts of the vocal tract, as shown in the Cervical Posteroanterior Radiography.

\section{Material and Methods}

\subsection{Participants}

Fifty-five (55) healthy singers (male: 27 ; female: 28 ), aged from 18 to 78 , were included in this study. The twenty-seven males were classified as follows: 1) 7 basses, 2) 12 baritones, and 3) 8 tenors. Likewise, the twenty-eight females were classified as: 1) 9 contraltos, 2) 12 mezzo-sopranos and 3) 7 sopranos (Table 1). All subjects were classified into singing groups by an experienced vocal coach, an ENT doctor and a speech therapist.

As known, the best way to categorize opera singers into groups, is the Fuch system. This system refers to the special kind of voice type, as is for example, the "high" dramatic soprano, required for the role of Isolde in Wagner's Tristan und Isolde. Therefore, the voice range is also very dependent inside a classification on the repertoire and the singers' Fach [61] [62] [63].

Although using Fach system would probably be the most helpful for opera singers, we used the typical voice classification of singing voice, without analyzing the voice category, because our research sample consists of professional nonopera singers.

The participants that had undergone prior head-neck area surgery or any type of laryngeal surgery were not included in this study. Additionally, subjects who had 
Table 1. Demographic data samples.

\begin{tabular}{ccccc}
\hline & Total group & Female & Male & p-level \\
$\mathbf{N}=\mathbf{5 5}$ & $\mathbf{N}=\mathbf{2 8}$ & $\mathbf{N}=\mathbf{2 7}$ & \\
\hline Age (years), mean (SD) & $36.90(16.70)$ & $39.04(12.90)$ & $36.20(13.50)$ & 0.362 \\
Height (cm), mean (SD) & $1.69(0.11)$ & $1.66(0.12)$ & $1.74(0.75)$ & 0.061 \\
Body Weight (Kg), mean (SD) & $70.12(16.63)$ & $67.28(12.16)$ & $75.16(12.02)$ & 0.099 \\
Years of Vocal Training, mean (SD) & $9.27(7.90)$ & $10.58(8.06)$ & $9.44(8.15)$ & 0.943 \\
Voice category & & & & \\
Bass & 7 & --- & 7 & \\
Baritone & 12 & --- & 12 & \\
Tenor & 8 & --- & 8 & \\
Contralto & 9 & 9 & --- & \\
Mezzo-soprano & 12 & 12 & --- & \\
Soprano & 7 & 7 & -- & \\
\hline
\end{tabular}

$\mathrm{p}<0.050,{ }^{* *} \mathrm{p}<0.005,{ }^{* * *} \mathrm{p}<0.001$.

presented during the previous two weeks with: (a) any upper or lower respiratory system disorder, (b) any laryngeal/vocal complaints, (c) symptoms of gastroesophageal reflux (GERD), or (d) laryngopharyngeal reflux (LRP) disease, were excluded, as well as subjects who had undergone voice therapy and/or presented voice disorders in the past. Moreover, the professional singers who were smokers, had a history of abuses (e.g., alcohol, recreational drugs, etc.), took medications proven to affect the voice (e.g., hormonal medication, inhaled steroids, etc.) or worked in environments where they were exposed to undue factors such as excessive dust or smoke, were also not included in this study [64]-[82].

The above data were obtained through a specific history form used in the ENT clinic of the University Hospital of Ioannina. Due to the above strict criteria, the study sample was limited to only 55 singers. It should be noted that potential female participants that were pregnant were also excluded from the study, because their receiving any radioactive substance would have been impermissible [83] [84]. This study was approved by the Ethical Committee of the Medical School, University of Ioannina.

\subsection{Collection of Data}

The sample was evaluated at the ENT clinic of the University Hospital of Ioannina, Greece. Prior to enrolment, each subject was informed of the research purposes and gave their written consent. For each participant, a video laryngeal stroboscopy and a teleradiographic study were conducted, both methods analysed as follows:

\subsubsection{Video Laryngeal Stroboscopy}

Each professional singer was given a stroboscopic evaluation of their larynx and 
vocal track area. The stroboscopic evaluation was chosen because it is a non-invasive method of introspection of vocal folds. During stroboscopy, each singer was asked to produce an /e/ sound at a frequency of tessitura. Tessitura refers to the prevailing note or range of notes in a vocal line, the most comfortable modal singing voice range) [85] [86] [87]. Additionally, the shape of the epiglottis (flat, omega shaped), the length (short, medium, long), the width of the vocal folds (narrow, wide, medium), the thickness (thin, coarse, medium) and the shape of the vocal folds (round shaped, striped shaped) were recorded. These evaluations were based on the subjective clinical examination of a single experimenter. The evaluation was performed using a rigid transoral Storz Stroboscope [88].

\subsubsection{Cervical Posteroanterior Radiography}

Cervical Posteroanterior Radiography was first introduced as chest radiography for pulmonary diseases and it is considered effective as an imaging method. All subjects underwent lateral cervical radiography in a posteroanterior (PA) position.

In order to achieve the lateral cervical radiography in (PA) position, we collaborated with a specialist from the radiology department of the University Hospital of Ioannina. The X-ray results were performed in the radiological laboratory of the University Hospital of Ioannina. Women were allowed to participate in the X-ray examination only after a negative urine pregnancy test. An X-ray contrast agent was not used, according to the standard protocol procedure [89] [90] [91] [92].

Each participant was positioned $180-200 \mathrm{~cm}$ away from the image receptors, erect and with a head inclination of $14^{\circ}$. During the imaging procedure, the singer was again asked to sing the /e/ vowel at the tessitura, as in the stroboscopic evaluation. In order for us to receive a lateral cervical view, subjects were sat in a neutral position, with head straight, as proposed in the literature. In order to acquire proper positioning, we strictly excluded any participants who did not fulfill the anatomic criteria. The measurements were obtained by extending a line drawn along the cervical incisor to the medulla of the hard palate (CI-MHP), from the medulla of the hard palate to the second cervical vertebra (MHP-SCV) and finally from the second cervical vertebra to the anterior incision (SCV-AI). Algorithms in literature are evaluated on PA views of adults' $\mathrm{X}$-rays with healthy anatomic imaging (Figure 2). Additionally, the phonetic area (PA) was measured, which was the sum of CI-MHP, the MHP-SCV and the SCV-AI $[\mathrm{PA}=\mathrm{CI}-\mathrm{MHP}+\mathrm{MHP}-\mathrm{SCV}+\mathrm{SCV}-\mathrm{AI}]$, as well as the oral-pharyngeal cavity (OPC) distance, which shows the mean length of the oral-pharyngeal cavity $[\mathrm{OPC}=\mathrm{CI}-\mathrm{MHP}+\mathrm{MHP}-\mathrm{SCV}]$. The head position, as well as the object position, in this technique does not change the image contouring. In order to reduce the radiation dose, $\mathrm{PA}$ projection was preferred to the traditional anteroposterior (AP) radiogram, as the radiation dose is much lower than that of the standard AR projection in cervical radiography [89]-[94]. 


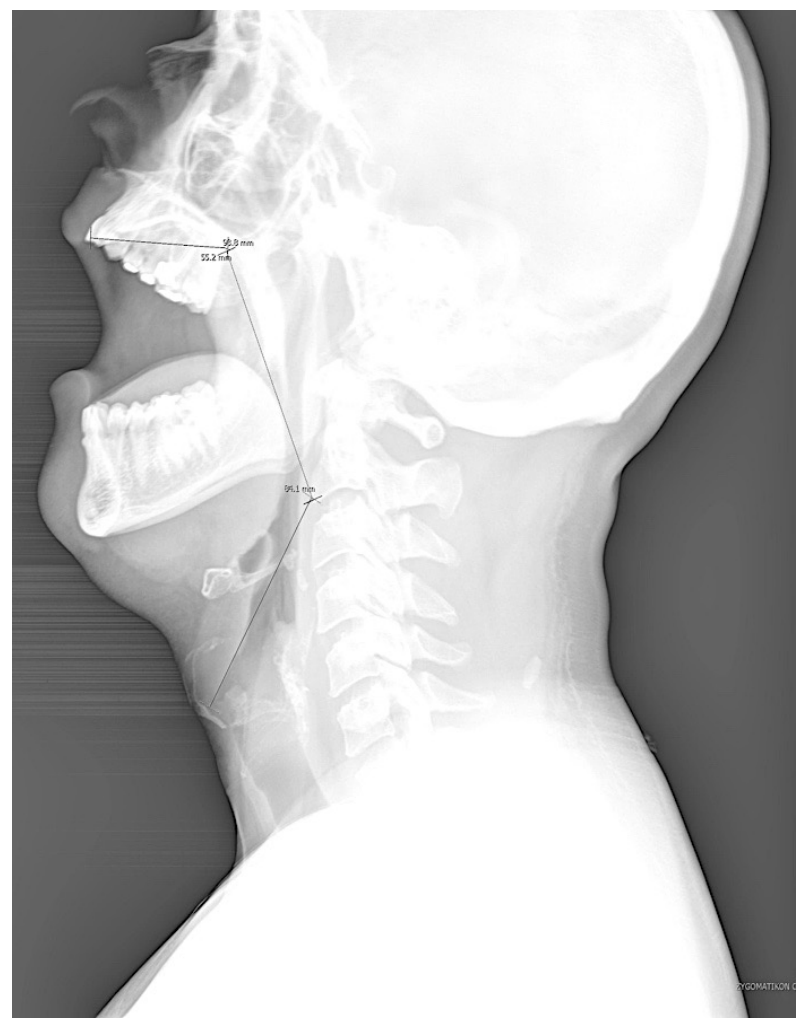

Figure 2. Cervical posteroanterior radiography. The participant is depicted while singing the /e/ vowel. In the picture, the lengths of the distances between the anatomical parts of the vocal tract, measured in millimeters, are marked.

Based on the standard protocol procedure, $\mathrm{X}$-rays with foreign bodies, false positive findings, calcifications and/or soft tissue and osseous masses were also excluded from our study. The above-mentioned dimensions were measured using electronic tools provided by the IMPAX program.

Although we used X-ray for physiologic question, we decided to choose this technique after taking into account realistic conditions and expectations. On the one hand, MRI technology would be harmless and could probably offer even more precise data. We found the limitations of this technique stronger than its efficacy. Firstly, we did not have easy access to this technique in our Hospital, because of the deficient equipment. Secondly, an anxious patient, a claustrophobic or a patient in pain, would find it difficult to accomplish. Patients with metal in their body, kidney or liver diseases would have to be excluded from the study. Finally, MRI scans take longer and cost more than other imaging tests such as a CT scan or X-ray and that was a really restrictive. In our opinion, these reasons led us to prefer the x-ray from the MRI technique [95] [96] [97] [98].

\subsubsection{Nasal-Sinus and Clinical Evaluation}

An ENT doctor obtained the medical history of each professional singer. A clinical evaluation of all participants was also performed to record the size of the oral cavity (small, medium, large) and the shape of the hard palate (oval, arcuate, flat). Moreover, the tone of the voice (acute, medium, heavy) and the voice con- 
tour (light, dark) were obtained as qualitative data. Finally, anterior rhinoscopy was used to evaluate the transparency of the nasal cavity (good, reduced) and the nasal structure (typical or with abnormalities). The instruments used were a small-sized Killian's Nasal Speculum and a headlight [98] [99] [100] [101] [102].

\subsection{Statistical Analysis}

The distribution of variables was tested using the Kolmogorov-Smirnov and Shapiro-Wilk tests. All skewed variables are expressed as the medians and the interquartile range, and all normally distributed variables are expressed as the means and standard deviations (SD). A repeated measures ANOVA model was used for the comparison of the study groups and the Cervical Posteroanterior Radiography findings. Additionally, ETA statistics were calculated. The Pearson rank correlation coefficient was used to correlate the vocal category of the participants with the PA and OPC. Furthermore, Spearman's rank correlation coefficient was used to correlate the vocal category of the participants and the permeability of nasal cavity, oral pharyngeal size, shape of the hard palate, epiglottis, length of the vocal folds, shape of the vocal folds, width of the vocal folds, thickness of the vocal folds, tone/tonicity of the speech, vocal timbre. All reported p-values were two-tailed, and the statistical significance was set at the value of $\mathrm{p}<0.05$. The analysis was performed with SPSS statistical software (version 19.0, Armonk, NY, USA).

\section{Results}

The mean age of the total sample was 36.90 yrs. $(S D=16.70)$ with the mean age of males at 36.20 yrs. $(S D=13.50)$ and the mean age of females at 39.04 yrs. (SD $=12.90)$ (Table 1).

The mean height of the total sample was 1.69 yrs. $(S D=0.11)$ with that for males being 1.74 yrs. $(S D=0.75)$ and for females 1.66 yrs. $(S D=0.12)$.

The mean body weight of the total sample was $70.12 \mathrm{Kg}$. $(\mathrm{SD}=16.63)$ with male mean body weight of $75.16 \mathrm{Kg}(\mathrm{SD}=12.02)$ and female mean body weight $67.28 \mathrm{Kg}$. $(\mathrm{SD}=12.16)$.

The mean years of vocal training for the total sample was $9.27 \mathrm{yrs}$. $(\mathrm{SD}=7.90)$ with mean male vocal training at 10.58 yrs. $(S D=8.06)$ and female mean vocal training at 9.44 yrs. $(\mathrm{SD}=8.15)$ (Table 1$)$.

A statistically significant difference was observed for the average height in centimeters of the male singers $\left[\mathrm{F}(2)=5.038, \mathrm{p}=0.016, \eta^{2}=0.032\right]$ with the basses being the tallest [Mean $=1.79, \mathrm{SD}=0.078$ ], followed by the tenors [Mean $=1.78, \mathrm{SD}=0.086]$ and lastly the baritones [Mean $=1.70, \mathrm{SD}=0.075$ ].

In contrast, non-statistically significant differences were observed for the average weight in kilograms for the male singers $\left[\mathrm{F}(2)=1.644 \mathrm{p}=0.213, \eta^{2}=\right.$ 0.013 ] with the tenors [Mean $=81.57, \mathrm{SD}=13.17$ ] having on average the heavier body weight, followed by the basses [Mean $=74.83, \mathrm{SD}=13.04$ ] and lastly the baritones $[$ Mean $=71.27, \mathrm{SD}=9.88]$. No statistically significant difference was 
observed for the average height in centimeters of the female singers $[\mathrm{F}(2)=$ $\left.1.887 \mathrm{p}=0.177, \eta^{2}=0.015\right]$ with the contraltos being the tallest [Mean $=1.74$, $\mathrm{SD}=0.086]$ followed by the mezzo-sopranos $[$ Mean $=1.65, \mathrm{SD}=0.142]$ and then by the sopranos [Mean $=1.62, \mathrm{SD}=0.124$ ].

Likewise, non-statistically significant differences were observed for the average weight in kilograms of the female singers $\left[\mathrm{F}(2)=2.404 \mathrm{p}=0.116, \eta^{2}=\right.$ 0.019 ] with the contraltos being the heaviest $[$ Mean $=79.86, \mathrm{SD}=15.97$ ] followed by the mezzo-sopranos $[$ Mean $=64.10, \mathrm{SD}=21.60$ ] and then by the sopranos [Mean $=57.92, \mathrm{SD}=17.23]$.

As regards the comparison of the mean distances in millimeters for the CI-MHP among all singers in the group, a statistically significant difference was observed $[F(5)=2.897, p=0.047]$, while a non-statistically significant difference of mean distances for the MHP-SCV was calculated $[F(5)=0.694, p=$ $0.631]$ among all the singers in the group. However, a statistically significant difference was observed $[\mathrm{F}(5)=3.150, \mathrm{p}=0.015]$ for the SCV-AI among all the singers in the group.

Likewise, for the average length measured in $\mathrm{mm}$ of the phonetic area PA, statistically significant differences were computed among all the singers in the group $[\mathrm{F}(5)=5.368, \mathrm{p}=0.001]$.

Statistically significant differences were also observed in the average distance which represents the mean length of the OPC for all the singers in the group [F $(5)=2.899, \mathrm{p}=0.023]($ Table 2$)$

Table 2. Comparison of mean distances using teleradiography among all singers.

\begin{tabular}{|c|c|c|c|c|c|}
\hline & $\begin{array}{l}{ }^{\dagger} \mathrm{CI}-\mathrm{MHPg} \\
\text { Mean (SD) }\end{array}$ & $\begin{array}{l}{ }^{\ddagger} \text { MHP-SCV } \\
\text { Mean (SD) }\end{array}$ & $\begin{array}{c}{ }^{6} \mathrm{SCV}-\mathrm{AI} \\
\text { Mean (SD) }\end{array}$ & $\begin{array}{c}\text { 'PA } \\
\text { Mean (SD) }\end{array}$ & $\begin{array}{c}\text { 'OPC } \\
\text { Mean (SD) }\end{array}$ \\
\hline $\begin{array}{c}\text { Bass } \\
(\mathrm{N}=7)\end{array}$ & $\begin{array}{l}59.38 \\
(6.83)\end{array}$ & $92.08(8.66)$ & $70.97(14.49)$ & $\begin{array}{l}219.12 \\
(26.12)\end{array}$ & $\begin{array}{l}151.34 \\
(12.27)\end{array}$ \\
\hline $\begin{array}{l}\text { Baritone } \\
(\mathrm{N}=12)\end{array}$ & $54.75(10.89)$ & $91.71(13.67)$ & $80.42(12.98)$ & $\begin{array}{l}227.08 \\
(14.38)\end{array}$ & $\begin{array}{l}148.58 \\
(12.01)\end{array}$ \\
\hline Tenor $(\mathrm{N}=8)$ & $\begin{array}{l}51.30 \\
(6.57)\end{array}$ & $91.46(11.55)$ & $72.61(19.71)$ & $\begin{array}{l}223.21 \\
(19.24)\end{array}$ & $\begin{array}{l}146.42 \\
(14.78)\end{array}$ \\
\hline $\begin{array}{c}\text { Contralto } \\
(\mathrm{N}=9)\end{array}$ & $\begin{array}{l}50.83 \\
(8.49)\end{array}$ & $85.47(8.59)$ & $\begin{array}{l}60.94 \\
(8.17)\end{array}$ & $\begin{array}{l}189.90 \\
(13.61)\end{array}$ & $\begin{array}{l}117.60 \\
(45.39)\end{array}$ \\
\hline Mezzo-soprano $(\mathrm{N}=12)$ & $\begin{array}{l}48.68 \\
(7.46)\end{array}$ & $86.01(10.34)$ & $67.16(10.33)$ & $\begin{array}{l}208.89 \\
(18.28)\end{array}$ & $\begin{array}{l}134.98 \\
(11.57)\end{array}$ \\
\hline $\begin{array}{c}\text { Soprano } \\
(N=7)\end{array}$ & $\begin{array}{l}48.84 \\
(3.87)\end{array}$ & $87.86(12.23)$ & $60.95(13.18)$ & $\begin{array}{l}202.90 \\
(20.92)\end{array}$ & $\begin{array}{l}137.65 \\
(15.61)\end{array}$ \\
\hline$F$ & 2.897 & 0.694 & 3.150 & 5.368 & 2.899 \\
\hline p-level & $0.047^{\star}$ & 0.631 & $0.015^{\star}$ & $0.001^{\star * *}$ & $0.023^{\star}$ \\
\hline
\end{tabular}

Abbreviations: ${ }^{\dagger} \mathrm{CI}-\mathrm{MHP}$, Central Incisor-Medulla Hard Palate; ${ }^{\ddagger} \mathrm{MHP}-\mathrm{SCV}$, Medulla Hard Palate-Second Cervical Vertebra; §SCV-AI, Second Cervical Vertebra-Anterior Incision Larynx, 9 PA, Phonetic Area; 9 OPC, Oral-pharyngeal Cavity. ${ }^{*} \mathrm{p}<0.050,{ }^{* *} \mathrm{p}<0.005,{ }^{* *} \mathrm{p}<0.001$. 
A statistically significant correlation (Pearson rho) between the vocal category and PA parameter differentiations for all the singers was observed via $[\mathrm{r}=$ $-0.402, \mathrm{p}=0.002]$.

Likewise, there was a statistically significant correlation between the voice category and SPC parameter differentiations for all the singers $[\mathrm{r}=-0.451, \mathrm{p}=$ $0.001]$.

Non-statistically significant differences were observed in the mean distance in millimeters of the CI-MHP area among the basses $(59.38 \mathrm{~mm}$; SD $=6.83)$, the baritones $(54.75 \mathrm{~mm}$; $\mathrm{SD}=10.89)$, and the tenors $(51.30 \mathrm{~mm}$; $\mathrm{SD}=6.57)$; [F (2) $=2.263, \mathrm{p}=0.129]$. However, a statistically significant difference was observed in the mean distance of the MHP-SCV area among the basses $(92.08 \mathrm{~mm}$; SD = $8.66)$, the baritones $(91.71 \mathrm{~mm}$; SD $=13.67)$, and the tenors $(91.46 \mathrm{~mm}$; $\mathrm{SD}=$ $11.55)$; $[\mathrm{F}(2)=0.101, \mathrm{p}=0.904]$. The average distance of the SCV-AI also differed to a statistically significant degree among the basses $(70.97 \mathrm{~mm}$; $\mathrm{SD}=$ $14.49)$, the baritones $(80.42 \mathrm{~mm} ; \mathrm{SD}=12.98)$ and the tenors $(72.61 \mathrm{~mm} ; \mathrm{SD}=$ 19.71); [F (2) =0.768, $\mathrm{p}=0.476]$.

Likewise, for the average length measured in $\mathrm{mm}$ of the phonetic area (PA), statistically significant differences were observed $[F(2)=0.017, p=0.983$ ] among the basses $(219.12 \mathrm{~mm}$; SD $=26.12)$, the baritones $(227.08 \mathrm{~mm}$; SD = $14.38)$ and the tenors $(223.21 \mathrm{~mm}$; $\mathrm{SD}=19.24)$.

Statistically significant differences were also observed in the average distance that represents the mean length of the stomatopharyngeal cavity, OPC, among the basses $(151.34 \mathrm{~mm}$; SD $=12.27)$, the baritones $(148.58 \mathrm{~mm} ; \mathrm{SD}=12.01)$ and the tenors (146.42 $\mathrm{mm}$; $\mathrm{SD}=14.78) ;[\mathrm{F}(2)=0.551, \mathrm{p}=0.584]$ (Table 3).

Similarly, non-statistically significant differences were observed in the mean distance in millimeters of the CI-MHP area $[\mathrm{F}(2)=1.417, \mathrm{p}=0.266]$ among the contraltos $(50.83 \mathrm{~mm}$; SD $=8.49)$, the mezzosopranos $(48.68 \mathrm{~mm}$; $\mathrm{SD}=7.46)$, and the sopranos $(48.84 \mathrm{~mm}$; $\mathrm{SD}=3.87)$. However, statistically significant differences were observed in the mean distance of the MHP-SCV area among the

Table 3. Comparison of mean distances using teleradiography among bass, baritone and tenor singers.

\begin{tabular}{cccccc}
\hline & $\begin{array}{c}{ }^{\dagger} \text { CI-MHPg } \\
\text { Mean (SD) }\end{array}$ & $\begin{array}{c}{ }^{\ddagger} \text { MHP-SCV } \\
\text { Mean (SD) }\end{array}$ & $\begin{array}{c}{ }^{5} \text { SCV-AI } \\
\text { Mean (SD) }\end{array}$ & $\begin{array}{c}{ }^{\text {SPA }} \\
\text { Mean (SD) }\end{array}$ & $\begin{array}{c}\text { 'OPC } \\
\text { Mean (SD) }\end{array}$ \\
\hline $\begin{array}{c}\text { Bass } \\
(\mathrm{N}=7)\end{array}$ & 59.38 & $92.08(8.66)$ & $70.97(14.49)$ & 219.12 & 151.34 \\
Baritone & $(6.83)$ & & & $(26.12)$ & $(12.27)$ \\
$(\mathrm{N}=12)$ & $54.75(10.89)$ & $91.71(13.67)$ & $80.42(12.98)$ & 227.08 & 148.58 \\
Tenor & 51.30 & & & $(14.38)$ & $(12.01)$ \\
$(\mathrm{N}=8)$ & $(6.57)$ & $91.46(11.55)$ & $72.61(19.71)$ & 223.21 & 146.42 \\
$F$ & 2.263 & 0.101 & 0.768 & 0.017 & 0.551 \\
p-level & 0.129 & 0.904 & 0.476 & 0.983 & 0.584 \\
\hline
\end{tabular}

Abbreviations: ${ }^{\dagger} \mathrm{CI}-\mathrm{MHP}$, Central Incisor-Medulla Hard Palate; ${ }^{\ddagger}$ MHP-SCV, Medulla Hard Palate-Second Cervical Vertebra; §SCV-AI, Second Cervical Vertebra-Anterior Incision Larynx, PA, Phonetic Area; OPC, Oral-pharyngeal Cavity. ${ }^{*} \mathrm{p}<0.050,{ }^{* *} \mathrm{p}<0.005,{ }^{* * *} \mathrm{p}<0.001$. 
contraltos $(85.47 \mathrm{~mm}$; $\mathrm{SD}=8.59)$, the mezzosopranos $(86.01 \mathrm{~mm} ; \mathrm{SD}=10.34)$ and the sopranos $(87.86 \mathrm{~mm} ; \mathrm{SD}=12.23)$; $[\mathrm{F}(2)=0.164, \mathrm{p}=0.150]$. The average distance of the SCV-AI also showed statistically significant differences in the mean distance of the MHP-SCV area among the contraltos $(67.16 \mathrm{~mm}$; SD = 10.33), the mezzo-sopranos $(60.94 \mathrm{~mm} ; \mathrm{SD}=8.17)$ and the sopranos $(60.95 \mathrm{~mm}$; $\mathrm{SD}=13.18) ;[\mathrm{F}(2)=1.066 \mathrm{p}=0.215]$.

For the average length measured in $\mathrm{mm}$ of the phonetic area (PA), statistically significant differences were observed $[\mathrm{F}(2)=1.663, \mathrm{p}=0.215]$ among the contraltos $(189.90 \mathrm{~mm} ; \mathrm{SD}=13.61)$, the mezzo-sopranos $(208.89 \mathrm{~mm}$; $\mathrm{SD}=18.28)$, and the sopranos $(202.90 \mathrm{~mm}$; $\mathrm{SD}=20.92)$.

Statistically significant differences were also observed in the average distance that represents the mean length of the oral pharyngeal cavity, OPC [F (2) = $0.962, \mathrm{p}=0.399]$, among the contraltos $(117.60 \mathrm{~mm}$; $\mathrm{SD}=45.39)$, the mezzo-sopranos $(134.98 \mathrm{~mm}$; $\mathrm{SD}=11.57)$, and the sopranos $(137.65 \mathrm{~mm} ; \mathrm{SD}=$ 15.61) (Table 4).

The Pearson rank correlation coefficient was used to correlate the vocal category of the participants with the PA and OPC areas for the total sample; that is, both the male and the female singers.

Statistically significant and negative correlations between voice category and PA area $(r=-0.451, p=0.001)$ as well as between voice category and OPC area $(\mathrm{r}=-0.402, \mathrm{p}=0.001)$ were found in the total sample.

Likewise, statistically significant and negative correlations between vocal category and PA area $(\mathrm{r}=-0.319, \mathrm{p}=0.047)$ as well as between vocal category and OPC area $(r=-0.328, p=0.044)$ were found in the case of the male singers. Similarly, statistically significant and negative correlations between vocal category and PA area $(\mathrm{r}=-0.336, \mathrm{p}=0.041)$ as well as between vocal category and OPC area $(r=-0.344, p=0.039)$ were found in the case of the female singers.

Furthermore, Spearman's rho analysis between the vocal category and the clinical characteristics of the participants was computed. Specifically, for the

Table 4. Comparison of mean distances using teleradiography among contralto, mezzo-soprano and soprano singers.

\begin{tabular}{|c|c|c|c|c|c|}
\hline & $\begin{array}{l}{ }^{\dagger} \text { CI-MHPg } \\
\text { Mean (SD) }\end{array}$ & $\begin{array}{l}{ }^{\ddagger} \mathrm{MHP}-\mathrm{SCV} \\
\text { Mean (SD) }\end{array}$ & $\begin{array}{c}{ }^{\text {SSCV-AI }} \\
\text { Mean (SD) }\end{array}$ & $\begin{array}{c}\text { 'PA } \\
\text { Mean (SD) }\end{array}$ & $\begin{array}{c}\text { 'OPC } \\
\text { Mean (SD) }\end{array}$ \\
\hline $\begin{array}{l}\text { Contralto } \\
(\mathrm{N}=9)\end{array}$ & $\begin{array}{l}50.83 \\
(8.49)\end{array}$ & 85.47 (8.59) & $\begin{array}{l}60.94 \\
(8.17)\end{array}$ & $\begin{array}{l}189.90 \\
(13.61)\end{array}$ & $\begin{array}{l}117.60 \\
(45.39)\end{array}$ \\
\hline Mezzo-soprano $(\mathrm{N}=12)$ & $\begin{array}{l}48.68 \\
(7.46)\end{array}$ & $86.01(10.34)$ & $67.16(10.33)$ & $\begin{array}{l}208.89 \\
(18.28)\end{array}$ & $\begin{array}{l}134.98 \\
(11.57)\end{array}$ \\
\hline $\begin{array}{c}\text { Soprano } \\
(N=7)\end{array}$ & $\begin{array}{l}48.84 \\
(3.87)\end{array}$ & $87.86(12.23)$ & $60.95(13.18)$ & $\begin{array}{l}202.90 \\
(20.92)\end{array}$ & $\begin{array}{l}137.65 \\
(15.61)\end{array}$ \\
\hline$F$ & 1.417 & 0.164 & 1.066 & 1.663 & 0.962 \\
\hline p-level & 0.266 & 0.850 & 0.363 & 0.215 & 0.399 \\
\hline
\end{tabular}

Abbreviations: ${ }^{\dagger} \mathrm{CI}-\mathrm{MHP}$, Central Incisor-Medulla Hard Palate; ${ }^{\ddagger} \mathrm{MHP}-\mathrm{SCV}$, Medulla Hard Palate-Second Cervical Vertebra; $\$ S C V-A I$, Second Cervical Vertebra-Anterior Incision Larynx, 9 PA, Phonetic Area; 9 OPC, Oral-pharyngeal Cavity. ${ }^{*} \mathrm{p}<0.050,{ }^{* *} \mathrm{p}<0.005,{ }^{* * *} \mathrm{p}<0.001$. 
sample in total, this analysis revealed no statistical significance between vocal category and permeability of nasal cavity ( $\mathrm{rs}=0.087, \mathrm{p}=0.527$ ); vocal category and oral-pharyngeal size ( $\mathrm{rs}=-0.008, \mathrm{p}=0.956)$; vocal category and shape of the hard palate ( $\mathrm{rs}=-0.049, \mathrm{p}=0.723$ ); voice category and epiglottis ( $\mathrm{rs}=$ $-0.164, \mathrm{p}=0.231$ ); vocal category and length of vocal folds ( $\mathrm{rs}=0.025, \mathrm{p}=$ 0.857 ); vocal category and shape of vocal folds ( $r s=0.189, \mathrm{p}=0.167$ ); vocal category and width of vocal folds ( $\mathrm{rs}=-0.062, \mathrm{p}=0.652)$; vocal category and thickness of the vocal folds ( $\mathrm{rs}=-0.217, \mathrm{p}=0.112$ ); vocal category and vocal tone $(\mathrm{rs}=-0.174, \mathrm{p}=0.205)$; and vocal category and timbre of voice( $\mathrm{rs}=0.215$, $\mathrm{p}=0.114)$.

For the male singers, Spearman's rho analysis revealed no statistical significance between vocal category and permeability of nasal cavity ( $\mathrm{rs}=-0.040, \mathrm{p}=$ 0.852 ); vocal category and oral-pharyngeal size ( $\mathrm{rs}=0.227, \mathrm{p}=0.286$ ); vocal category and shape of the hard palate ( $\mathrm{rs}=-0.036, \mathrm{p}=0.868$ ); vocal category and epiglottis ( $\mathrm{rs}=-0.182, \mathrm{p}=0.395$ ); vocal category and length of vocal folds ( $\mathrm{rs}=$ $-0.281, \mathrm{p}=0.183$ ); vocal category and shape of vocal folds ( $\mathrm{rs}=-0.065, \mathrm{p}=$ $0.765)$; vocal category and width of vocal folds ( $\mathrm{rs}=-0.062, \mathrm{p}=0.652$ ); vocal category and thickness of vocal folds ( $\mathrm{rs}=0.196, \mathrm{p}=0.359)$; vocal category and vocal tone ( $\mathrm{rs}=-0.023, \mathrm{p}=0.915)$; and vocal category and timbre of voice ( $\mathrm{rs}=$ $-0.053, \mathrm{p}=0.804)$.

For the female singers, analysis also revealed no statistical significance between vocal category and permeability of nasal cavity ( $r s=0.038, p=0.863$ ); vocal category and size of oro-pharynx ( $\mathrm{rs}=0.227, \mathrm{p}=0.286$ ); vocal category and shape of the hard palate ( $\mathrm{rs}=-0.036, \mathrm{p}=0.868$ ); vocal category and epiglottis ( $r s=-0.182, p=0.395$ ); vocal category and length of vocal folds ( $r s=-0.281$, $\mathrm{p}=0.183)$; vocal category and shape of vocal folds $(\mathrm{rs}=-0.282, \mathrm{p}=0.181)$; vocal category and width of vocal folds ( $\mathrm{rs}=-0.065, \mathrm{p}=0.763$ ); vocal category and thickness of vocal folds ( $\mathrm{rs}=0.196, \mathrm{p}=0.359$ ); vocal category and vocal tone ( $\mathrm{rs}$ $=-0.023, \mathrm{p}=0.915)$; and vocal category and timbre of voice $(\mathrm{rs}=-0.053, \mathrm{p}=$ $0.804)$.

The objective examination based on stroboscopy clinical findings showed that $66.6 \%$ of the male singers had good transparency of the nasal cavity, while $33.3 \%$ of them had reduced transparency.

For the female singers, $72.72 \%$ had good transparency of the nasal cavity while $27.27 \%$ had reduced transparency. $27.7 \%$ of the male singers possessed a small stomatopharynx, $44.4 \%$ mean size and $27.7 \%$ large. In the female singers, $54.4 \%$ possessed a small stomatopharynx, $31.81 \%$ mean sized and $13.63 \%$ large. $44.44 \%$ of the male singers presented an oval-shaped palate, $38.88 \%$ arched and $16.66 \%$ flat hard palate. Correspondingly, $59.09 \%$ of the female singers presented an oval hard palate, $22.72 \%$ had an arched palate, and the same percentage $(22.72 \%)$ possessed a flat shaped hard palate. Regarding the shape of the epiglottis, $44.44 \%$ of the male singers had a high-rising epiglottis, while $55.55 \%$ of them had a lower-lying epiglottis. $63.63 \%$ of the female singers were found to have a high-rising 
epiglottis, and $36.36 \%$ of them with a lower-lying epiglottis. Concerning the length of vocal folds, in $33.33 \%$ of the male singers these were short, in $55.55 \%$ average length and in $11.11 \%$ long.

Similarly, in the female opera singers, $36.36 \%$ had short vocal folds, $45.45 \%$ average length and $18.18 \%$ long. In terms of the shape of the vocal folds, the following were found: in $66.66 \%$ of the male singers these were rounded and in $33.33 \%$ elongated. In the female singers, $40.90 \%$ had rounded vocal folds and $59.09 \%$ elongated.

Concerning the category of vocal folds, $38.88 \%$ of the male singers exhibited narrow vocal folds, $44.44 \%$ wide and $16.66 \%$ medium size. $50 \%$ of the female singers had narrow vocal folds, $27.27 \%$ of them wide and $22.72 \%$ medium size. The thickness of the vocal folds was found to be thin in $33.33 \%$ of the men, thick in $44.44 \%$ and of average thickness in $22.22 \%$.

Correspondingly, $59.09 \%$ of the female singers were found to have thin vocal folds, $27.27 \%$ thick and $13.63 \%$ of average thickness. The tone of speech was average in $22.22 \%$ of the male singers acute in $22.22 \%$, and heavy in $55.55 \%$. In $40.90 \%$ of the female singers, the tone of voice was medium, in $36.36 \%$ acute and in $22.72 \%$ heavy.

Finally, in observing the colour of each participant's speech, it was found that $61.11 \%$ of the male singers exhibited deep voice colour, and $38.88 \%$ high-tone voice colour. In the female singers, $40.90 \%$ exhibited deep voice colour, and $59.09 \%$ high-tone voice colour.

\section{Discussion}

This study attempted to correlate morphometrically, through the use of video laryngeal stroboscopy and cervical posteroanterior radiography, the vocal category of professional singers with their oropharyngeal and laryngeal anatomy. This was achieved through the collection of data on 55 healthy singers. The male singers included basses, baritones and tenors and the female singers were contraltos, mezzo-sopranos and sopranos. The statistical analysis of the data included the determination of mean distances in $\mathrm{mm}$ and the correlations of the VC of the professional singers (classified into six singing groups) with the findings of the aforementioned two imaging techniques, and with the clinical evaluation data.

The results showed statistically significant differences among all the singers for CI-MHP, SCV-AI, PA and OPC. In contrast with the above, non-statistically significant differences among the male singers were observed for all measured distances (CI-MHP, MHP-SCV, SCV-AI, PA, OPC), with the same result being observed for the female singers.

Specifically, the mean distance of CI-MHP in $\mathrm{mm}$ appears proportional to the VC. The longest distance appears in basses, is shorter in baritones and the shortest in tenors. The CI-MHP distance in $\mathrm{mm}$ measured in the female professional singers also appeared proportionally, with the Contraltos having the 
longest mean distance and the Mezzo-sopranos the shortest. Our results show that the shape of hard palate affects the vocal category, in such a way that allows us to posit the following for consideration: singers with a dome-shaped hard palate will probably exhibit a low frequency of VC. Our results failed to provide support for Roers, Mürbe and Sundberg's [53] notion of there being no systematic variation of palate height and singer voice classification. On the contrary, our findings agree with those of Gutzmann [98] that the height of the palatal arch varies systematically with singer voice classification. Our results also agreed with those of Gutzmann in that the shape of hard palate affects vocal category: Gutzmann claims that singers with a high hard palate are categorized into singing groups with high frequency vocal range, such as tenors and soprano.

The role of resonance and vibration of the hard palate in singing has already been discussed by many researchers and using various methods [57] [102]. Gates in 1998 [101] noticed that lifting on the opening between soft and hard palate, combined with the extension of the ribs, influences the vocal pitch. Similar results are reported by Lammert et al. [102], suggesting that the palatal concavity is a major source of morphological variation that effects speech, articulation and acoustics.

We also noticed that the SCV-AI distance was the longest in singers with middle frequency of voice category, both male and female (Table 2). This distance between the second vertebra of the spine and the anterior incision of vocal folds in fact represents the distance between the larynx and the spine while singing. The influence of the larynx position in singing production has been mentioned in several other studies [1] [60] [104] [106] [107]. Specifically, Shipp [103] found that, when the larynx is raised while singing, the laryngeal muscles move and change vocal pitch. Wang [103] suggested that, although a singer's high formant is associated with different larynx position, lowering the larynx does not explain the extra formant production, or the singer's formant and voice quality. Based on Cleveland's observations [98], the larynx can rise in certain tenors and certain female voices. According to the above studies, we notice that they do not prove a specific correlation between voice classification and larynx position while singing, as this research does. Taking this into account, together with the fact that the dimensions of the cervical vertebrae varied between individuals, we can say that we expected results not to categorize the different types of singing voices into groups based on the larynx position while singing. Sonninen, Hurme and Laukkanen [105], using radiographic imagining methods, observed a female singer while singing and noted that singing voice production involves complex movements of the laryngeal structures.

In this study, the OPC distance in $\mathrm{mm}$ was also measured. The OPC represents the length of oropharynx correlated to voice category. We found that it was inversely proportional to the frequency range in both the male and the female singers [28]. Singers with a low voice category, such as male basses, exhibit the longest length of oropharynx, while female soprano singers have the 
shortest length of oropharynx. Our results lead us to the same conclusion as that of Roers et al. [54].

The phonetic area (PA) that represents the sum of all distances was also measured and found not to be proportional to the VC but appeared to have the longest length in singers with middle frequencies of VC, both in men and women. This agrees with Roers' suggestion that the variation of the total vocal tract length is more dependent on the length of the pharynx cavity than on the length of the mouth cavity [53] [54].

In the literature, it is also reported that statistically significant correlations occur between voice category and the length of the vocal folds [54]. This contrasts with the results of our study, since non-statistically significant correlation was detected. This can be explained by the fact that the data collected for this parameter was nonnumeric.

Finally, in this present study, a correlation was made of the average height (measured in $\mathrm{cm}$ ) of singers with their voice category. A statistically significant difference was observed in the male singers, with the basses having the highest average body height, followed by the tenors and finally the baritones. As for the female singers, non-statistically significant differences were observed, as also reported by Roers et al. in 2009 [54]. Furthermore, we correlated the average body mass with voice category, since studies report that there is a significant influence [52] [53]. However, in this study, non-statistically significant correlations were observed between body mass and the voice classification.

\section{Conclusion}

In conclusion, this study aimed to provide an evidence-based classification of the voices of professional singers by correlating head and neck area distances via posteroanterior radiography and the larynx stroboscopic method [108] [109] [110]. We found that the height of the dome of the hard palate does correlate with voice category, both in male and female professional singers. This distance appears to be longer in singers with a low frequency voice category, such as male basses, and shorter in singers with a high frequency voice category, such as female sopranos. Both the SCI-AI distance (which represents the distance between the spine and the larynx) and the phonetic area PA seem to be longer in singers with middle frequency voice category, both in men and women. Following the conclusions of past studies, we confirmed that the lower the voice category, the longer the length of the oropharynx, both in male and female singers. Thus, a male bass has a long oropharynx, while a female soprano has a short one. We also measured the average height in our sample and ended up with the same result as previous studies. Singers with low frequency voices appear to be taller while singers with a high voice category seem to be shorter. Although many research studies support the fact that body mass influences the voice classification, we did not observe statistically significant differences between the average weight measured in kilograms and the voice cat- 
egory.

\section{Limitations}

Sample size was a limitation in this study. The effect sizes were good for all the comparisons of distances (Cohen's $d=0.74,95 \%$ CI [-48.39, 49.87]) based on the sample size of 55 participants. It was not feasible to recruit more participants due to COVID-19 restriction laws. Taking into account these effect size limitations, the results of this study are good but more participants would increase their validity.

\section{Conflicts of Interest}

The authors declare no conflicts of interest regarding the publication of this paper.

\section{References}

[1] Kayes, G. (2019) Structure and Function of the Singing Voice. In: Welch, G.F., Howard, D.M. and Nix, J., Eds., The Oxford Handbook of Singing, Oxford University Press, Oxford, 1-42.

[2] Rubin, J.S., Sataloff, R.T. and Korovin, G.S. (2014) Diagnosis and Treatment of Voice Disorders. Plural Publishing.

[3] Rubin, J.S., Blake, E. and Mathieson, L. (2007) Musculoskeletal Patterns in Patients with Voice Disorders.Journal of Voice, 21, 477-484.

https://doi.org/10.1016/j.jvoice.2005.02.001

[4] Sundberg, J. and Kullberg, A.. (2009) Voice Source Studies of Register Differences in Untrained Female Singing. Logopedics Phoniatrics Vocology, 24, 76-83. https://doi.org/10.1080/140154399435147

[5] Sundberg, J. (2018) The Singing Voice. In: Welch, G.F., Howard, D.M. and Nix, J., Eds., The Oxford Handbook of Voice Perception, Oxford University Press, Oxford, $10-45$.

[6] Kadakia, S., Carlson, D. and Sataloff, R.T. (2013) The Effect of Hormones on the Voice. Journal of Singing, 69, 571-574.

[7] Titze, I.R. (1994) Mechanical Stress in Phonation. Journal of Voice, 8, 99-105. https://doi.org/10.1016/S0892-1997(05)80302-9

[8] Sataloff, R.T. (1992) The Human Voice. Scientific American, 267, 108-115. https://doi.org/10.1038/scientificamerican1292-108

[9] Adessa, M., Stadelman-Cohen, T., Zipse, L., Guarino, A.J. and Heaton, J.T. (2018) Factors Affecting Voice Therapy Completion in Singers. Journal of Voice, 32, 564-571. https://doi.org/10.1016/j.jvoice.2017.06.021

[10] Emilia, P., Maximilian, S., Anton, B., Simone, H., Costantini, G., Klaus, S. and Schuller, B. (2018) Identifying Emotions in Opera Singing: Implications of Adverse Acoustic Conditions. 19th International Society for Music Information Retrieval Conference (ISMIR 2018), Paris, 23-27 September 2018.

[11] Eyben, F., Salomão, G.L., Sundberg, J., Scherer, K.R. and Schuller, B.W. (2015) Emotion in the Singing Voice-A Deeper Look at Acoustic Features in the Light of Automatic Classification. EURASIP Journal on Audio, Speech, and Music Processing, 2015, Article No. 19. https://doi.org/10.1186/s13636-015-0057-6 
[12] Gray, C.C. (2018) Relationship between Vocal Fatigue and Physical/Psychological Factors in Prospective Vocal Professionals. Master Thesis, University of South Florida.

[13] Bullack, A., Gass, C., Nater, U.M. and Kreutz, G. (2018) Psychobiological Effects of Choral Singing on Affective State, Social Connectedness, and Stress: Influences of Singing Activity and Time Course. Frontiers in Behavioral Neuroscience, 12, Article No. 223. https://doi.org/10.3389/fnbeh.2018.00223

[14] Nagy-Sandorand, Z. and Berkers, P. (2018) Culture, Heritage, Art: Navigating Authenticities in Contemporary Hungarian Folk Singing. Cultural Sociology, 12, 400-417. https://doi.org/10.1177\%2F1749975518780770

[15] Ray, C., Trudeau, M.D. and McCoy, S. (2018) Effects of Respiratory Muscle Strength Training in Classically Trained Singers. Journal of Voice, 32, 644.e25-644.e34. https://doi.org/10.1016/j.jvoice.2017.08.005

[16] Clarós, P., Sobolewska, A.Z., Doménech-Clarós, A., Clarós-Pujol, A., Pujol, C. and Clarós, A. (2019) CT-Based Morphometric Analysis of Professional Opera Singers' Vocal Folds. Journal of Voice, 33, 583.E1-583.E8. https://doi.org/10.1016/j.jvoice.2018.02.010

[17] Borgard, H.L., Baab, K., Pasch, B. and Riede, T. (2019) The Shape of Sound: A Geometric Morphometrics Approach to Laryngeal Functional Morphology. Journal of Mammalian Evolution, 27, 577-590. https://doi.org/10.1007/s10914-019-09466-9

[18] Ramli, M.I., Hamzaid, N.A. and Engkasan, J.P. (2019) Monitoring Breathing Muscle Performance during Singing Noninvasively Using Mechanomyography and Electromyography. Journal of Voice, 34, 862-869. https://doi.org/10.1016/j.jvoice.2019.06.006

[19] Hopewell, B.L., Paige, C. and Francis, D.O. (2019) An Unusual Etiology of Vocal Tremor in a Professional Singer. Journal of Voice, 33, 730-731. https://doi.org/10.1016/j.jvoice.2018.03.007

[20] Caffier, P.P., Nasr, A.I., Rendon, M.D.M.R., Wienhausen, S., Forbes, E., Seidner, W. and Nawka, T. (2018) Common Vocal Effects and Partial Glottal Vibration in Professional Nonclassical Singers. Journal of Voice, 32, 340-346. https://doi.org/10.1016/j.jvoice.2017.06.009

[21] Unteregger, F., Thommen, J., Honegger, F., Potthast, S., Zwicky, S. and Storck, C. (2019) How Age and Frequency Impact the Thyroid Cartilages of Professional Singers. Journal of Voice, 33, 284-289. https://doi.org/10.1016/j.jvoice.2017.11.017

[22] Ternström, S., D’Amario, S. and Selamtzis, A. (2018) Effects of the Lung Volume on the Electroglottographic Waveform in Trained Female Singers. Journal of Voice, 34, 485.e1-485.e21. https://doi.org/10.1016/j.jvoice.2018.09.006

[23] Mürbe, D., Roers, F. and Sundberg, J. (2011) Voice Classification in Professional Singers: The Influence of Vocal Fold Length, Vocal Tract Length and Body Measurements. $H N O$, 59, 556-562. https://doi.org/10.1007/s00106-011-2304-1

[24] Johnson, G. and Skinner, M. (2009) The Demands of Professional Opera Singing on Cranio-Cervical Posture. European Spine Journal, 18, Article No. 562. https://doi.org/10.1007/s00586-009-0884-1

[25] Vos, R.R., Murphy, D.T., Howard, D.M. and Daffern, H. (2018) Determining the Relevant Criteria for Three-Dimensional Vocal Tract Characterization. Journal of Voice, 32, 130-142. https://doi.org/10.1016/j.jvoice.2017.04.001

[26] Cho, W., Hong, J. and Park, H. (2012) Real-Time Ultrasonographic Assessment of True Vocal Fold Length in Professional Singers. Journal of Voice, 26, 819.E1-819.E6. 
https://doi.org/10.1016/j.jvoice.2012.05.007

[27] Zimmermann, D. (1938) Die Mazung der Stimmlippenlange bei Sangern und Sangerinnen. Arch. Arch. Sprach-u, 2, Article No. 103.

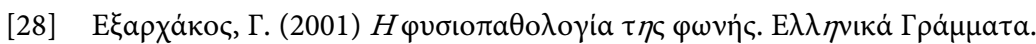

[29] Run, W.N. and Chung, Y.S. (1983) Roentgenological Measurement of Physiological Vocal Cord Length. An Analysis of 59 Opera Singers. Folia Phoniatrica et Logopaedica, 35, 289-293. https://doi.org/10.1159/000265704

[30] Frič, M. and Pavlechová, A. (2019) Listening Evaluation and Classification of Female Singing Voice Categories. Logopedics Phoniatrics Vocology, 45, 97-109. https://doi.org/10.1080/14015439.2018.1551418

[31] Chapman, J.L. (2016) Singing and Teaching Singing: A Holistic Approach to Classical Voice. Plural Publishing.

[32] Shipley, G.K. and McAfee, J.G. (2015) Assessment in Speech-Language Pathology: A Resource Manual. 4th Edition, Nelson Education.

[33] Callaghan, J., Emmons, S. and Popeil, L. (2018) Solo Voice Pedagogy. In: McPherson, G.E. and Weleh, G.F., Eds., Vocal, Instrumental, and Ensemble Learning and Teaching: An Oxford Handbook of Music Education, Oxford University Press, Oxford.

[34] Hegde, M.N. and Freed, D.F. (2011) Assessment of Communication Disorders in Adults, Resourses and Protocols. 2nd Edition, Plural Publishing.

[35] Clarós, P., Ribeiro, I., Clarós-Pujol, A., Pujol, C. and Clarós, A. (2019) An Opera Singer's Voice Mutation over Time Due to Acromegaly. Journal of Voice. https://doi.org/10.1016/j.jvoice.2019.03.010

[36] Erickson, M.L., Burchard, J. and Phillips, P. (2018) Can Listeners Hear Who Is Singing? The Development of Voice Category Perception. Journal of Voice, 32, 459-465. https://doi.org/10.1016/j.jvoice.2017.06.016

[37] Rubin, A.D. and Codino, J. (2019) The Art of Caring for the Professional Singer. Otolaryngologic Clinics of North America, 52, 769-778. https://doi.org/10.1016/j.otc.2019.03.019

[38] Johnson, A.M. and Kempster, G.B. (2011) Classification of the Classical Male Singing Voice Using Long-Term Average Spectrum. Journal of Voice, 25, 538-543. https://doi.org/10.1016/j.jvoice.2010.05.009

[39] Ortiz, A.J., Toles, L.E., Marks, K.L., Capobianco, S., Mehta, D.D., Hillman, R.E. and Van Stan, J.H. (2019) Automatic Speech and Singing Classification in Ambulatory Recordings for Normal and Disordered Voices. The Journal of the Acoustical Society of America, 146, EL22-EL27. https://doi.org/10.1121/1.5115804

[40] White, B.D. (1982) Singing and Science. The Journal of Laryngology \& Otology, 96, 141-157. https://doi.org/10.1017/S0022215100092343

[41] Su, M.C., Yeh, T.H., Tan, C.T., Lin, C.D., Linne, O.C. and Lee, SY. (2002) Measurement of Adult Vocal Fold Length. The Journal of Laryngology \& Otology, 116, 447-449. https://doi.org/10.1258/0022215021911257

[42] Lovato, A., Barillari, M.R., Giacomelli, L., Gamberini, L.L. and de Filippis, C. (2019) Predicting the Outcome of Unilateral Vocal Fold Paralysis: A Multivariate Discriminating Model Including Grade of Dysphonia, Jitter, Shimmer, and Voice Handicap Index-10. Annals of Otology, Rhinology \& Laryngology, 128, 447-452. https://doi.org/10.1177\%2F0003489419826597

[43] Weekly, E.M., Carroll, L.M., Korovin, G.S. and Fleming, R. (2018) A Vocal Health Survey among Amateur and Professional Voice Users. Journal of Voice, 32, 
474-478. https://doi.org/10.1016/j.jvoice.2017.07.012

[44] Festeu, A. (2018) Voice Classification: Terminology and Practicality. Bulletin of the Transilvania University of Braşov, Series VIII: Performing Arts, 11, 41-52.

[45] Erickson, M.L. (2020) Inexperienced Listeners' Perception of Timbre Dissimilarity within and between Voice Categories. Journal of Voice, 34, 302.E1-302.E13. https://doi.org/10.1016/j.jvoice.2018.09.012

[46] Cleveland, T.F. (1977) Acoustic Properties of Voice Timbre Types and Their Influence on Voice Classification. The Journal of the Acoustical Society of America, 61, 1622-1629. https://doi.org/10.1121/1.381438

[47] Jones, A. (2019) Singing High. In: Eidsheim, N.S. and Meizel, K., Eds., The Oxford Handbook of Voice Studies, Oxford University Press, Oxford.

[48] Nguyen, A. (2015) How Vocal Classification Affects Young Singers. Portland State University, Portland. https://doi.org/10.15760/honors.129

[49] Dmitriev, L. and Kiselev, A. (1979) Relationship between the Formant Structure of Different Types of Singing Voices and the Dimensions of Supraglottic Cavities. Folia Phoniatrica et Logopaedica, 31, 238-241. https://doi.org/10.1159/000264170

[50] Neng Run, W. and Siao Chung, Y. (1983) Roentgenological Measurement of Physiological Vocal Cord Length. An Analysis of 59 Opera Singers. Folia Phoniatrica et Logopaedica, 35, 289-293. https://doi.org/10.1159/000265704

[51] Arens, C., Dreyer, T., Glanz, H. and Malzahn, K. (2003) Compact Endoscopy of the Larynx. Annals of Otology, Rhinology \& Laryngology, 112, 113-119. https://doi.org/10.1177\%2F000348940311200203

[52] Jackson, M.C.A. (1982) La voix du jeune chanteur. Folia Phoniatrica et Logopaedica, 34, 276-280. https://doi.org/10.1159/000265664

[53] Roers, F., Mürbe, D. and Sundberg, J. (2009) Predicted Singers' Vocal Fold Lengths and Voice Classification-A Study of X-Ray Morphological Measures. Journal of Voice, 23, 408-413. https://doi.org/10.1016/j.jvoice.2007.12.003

[54] Roers, F. (2009) Voice Classification and Vocal Tract of Singers: A Study of X-Ray Images and Morphology. The Journal of the Acoustical Society of America, 125, 503-512. https://doi.org/10.1121/1.3026326

[55] Sonninen, A. and Hurme, P. (1998) Vocal Fold Strain and Vocal Pitch in Singing: Radiographic Observations of Singers and Non-Singers. Journal of Voice, 12, 274-286. https://doi.org/10.1016/S0892-1997(98)80018-0

[56] Yamasaki, R., Behlau, M., do Brasil, O.D.O.C. and Yamashita, H. (2011) MRI Anatomical and Morphological Differences in the Vocal Tract between Dysphonic and Normal Adult Women. Journal of Voice, 25, 743-750. https://doi.org/10.1016/j.jvoice.2010.08.005

[57] Benninger, M.S. (2011) The Professional Voice. The Journal of Laryngology \& Otology, 125, 111-116. https://doi.org/10.1017/S0022215110001970

[58] Wilson, S.J., Abbott, D.F., Lusher, D., Gentle, E.C. and Jackson, G.D. (2011) Finding Your Voice: A Singing Lesson from Functional Imaging. Human Brain Mapping, 32, 2115-2130.

[59] Vorik, A., Unteregger, F., Zwicky, S., Schiwowa, J., Potthast, S. and Storck, C. (2017) Three-Dimensional Imaging of High-Resolution Computer Tomography of Singers' Larynges-A Pilot Study. Journal of Voice, 31, 115e17-115e21. https://doi.org/10.1016/j.jvoice.2016.03.011

[60] Pullon, B. (2017) Relationship of the Cricothyroid Space with Vocal Range in Female Singers. Journal of Voice, 31, 125.e17-125.e23. 
https://doi.org/10.1016/j.jvoice.2015.11.026

[61] McGinnis, P.Y. (2010) The Opera Singer's Career Guide: Understanding the European Fach System. Scarecrow Press.

[62] Cotton, S. (2007) Voice Classification and Fach: Recent, Historical and Conflicting Systems of Voice Categorization. Doctoral Dissertation, University of North Carolina at Greensboro.

[63] Ball, R.C. (2017) The Development of a Fach System for the Tenor Oratorio Repertoire. James Madison University, St. Harrisonburg, VA.

[64] Al-Yahya, S.N., Muhammad, R., Suhaimi, S.N., Azman, M., Mohamed, A.S. and Baki, M.M. (2019) Selective Laryngeal Examination: Sensitivity of Endocrine Surgeons in Screening Voice Abnormality. Journal of Voice, 34, 811.E13-811.E20. https://doi.org/10.1016/j.jvoice.2018.12.003

[65] Debruyne, F., Ostyn, F., Delaere, P. and Wellens, W. (1997) Acoustic Analysis of the Speaking Voice after Thyroidectomy. Journal of Voice, 11, 479-482.

https://doi.org/10.1016/S0892-1997(97)80046-X

[66] Petrovic-Lazic, M., Jovanovic, N., Kulic, M., Babac, S. and Jurisic, V. (2015) Acoustic and Perceptual Characteristics of the Voice in Patients with Vocal Polyps after Surgery and Voice Therapy. Journal of Voice, 29, 241-246. https://doi.org/10.1016/j.jvoice.2014.07.009

[67] Štajner-Katušić, S., Horga, D. and Zrinski, K.V. (2008) A Longitudinal Study of Voice before and after Phonosurgery for Removal of a Polyp. Clinical Linguistics \& Phonetics, 22, 857-863. https://doi.org/10.1080/02699200802130813

[68] Chernobelsky, S.I. (2007) The Treatment and Results of Voice Therapy amongst Professional Classical Singers with Vocal Fold Nodules. Logopedics Phoniatrics Vocology, 32, 178-184. https://doi.org/10.1080/14015430600852043

[69] Dejonckere, M.P.H., Bradley, P., Clemente, P., Cornut, G., Crevier-Buchman, L., Friedrich, G., et al. (2001) A Basic Protocol for Functional Assessment of Voice Pathology, Especially for Investigating the Efficacy of (Phonosurgical) Treatments and Evaluating New Assessment Techniques. European Archives of Oto-Rhino-Laryngology, 258, 77-82. https://doi.org/10.1007/s004050000299

[70] Hicks, M., Brugman, S.M. and Katial, R. (2008) Vocal Cord Dysfunction/Paradoxical Vocal Fold Motion. Prim Care. Clinics in Office Practice, 35, 81-103. https://doi.org/10.1016/j.pop.2007.09.005

[71] Johns, M.M. (2003) Update on the Etiology, Diagnosis, and Treatment of Vocal Fold Nodules, Polyps, and cysts. Current Opinion in Otolaryngology \& Head and Neck Surgery, 11, 456-461. https://doi.org/10.1097/00020840-200312000-00009

[72] Shih, L.C., Piel, J., Warren, A., Kraics, L., Silver, A., Vanderhorst, V., et al. (2012) Singing in Groups for Parkinson's Disease (SING-PD): A Pilot Study of Group Singing Therapy for PD-Related Voice/Speech Disorders. Parkinsonism \& Related Disorders, 18, 548-552. https://doi.org/10.1016/j.parkreldis.2012.02.009

[73] Merati, A.L., Heman-Ackah, Y.D., Abaza, M., Altman, K.W., Sulica, L. and Belamowicz, S. (2005) Common Movement Disorders Affecting the Larynx: A Report from the Neurolaryngology Committee of the AAO-HNS. Otolaryngology-Head and Neck Surgery, 133, 654-665. https://doi.org/10.1016\%2Fj.otohns.2005.05.003

[74] Tafiadis, D., Helidoni, M.E., Chronopoulos, S.K., Kosma, E.I., Alexandropoulou, A., Ziavra, N. and Velegrakis, G.A. (2019) The Hellenic Voice Handicap Index of Different Laryngeal Mass Lesions: A Receiver-Operating Characteristic Analysis. Journal of Voice, 34, 966.E1-966.E10. https://doi.org/10.1016/j.jvoice.2019.06.016

[75] Ebersole, B., Soni, R.S., Moran, K., Lango, M., Devarajan, K. and Jamal, N. (2018) 
The Influence of Occupation on Self-Perceived Vocal Problems in Patients with Voice Complaints. Journal of Voice, 32, 673-680. https://doi.org/10.1016/j.jvoice.2017.08.028

[76] Kwok, M. and Eslick, G.D. (2019) The Impact of Vocal and Laryngeal Pathologies among Professional Singers: A Meta-Analysis. Journal of Voice, 33, 58-65. https://doi.org/10.1016/j.jvoice.2017.09.002

[77] Tafiadis, D., Helidoni, M.E., Chronopoulos, S.K., Kosma, E.I., Ziavra, N. and Velegrakis, G.A. (2020) Cross-Cultural Adaptation and Validation of the Greek Voice Handicap Index-10 (GVHI-10) with Additional Receiver Operating Characteristic Analysis. Journal of Voice, 34, 304.E1-304.E8. https://doi.org/10.1016/j.jvoice.2018.09.009

[78] Tafiadis, D., Chronopoulos, S.K., Helidoni, M.E., Kosma, E.I., Voniati, L., Papadopoulos, P., et al. (2019) Checking for Voice Disorders without Clinical Intervention: The Greek and global VHI Thresholds for Voice Disordered Patients. Scientific Reports, 9, Article No. 9366. https://doi.org/10.1038/s41598-019-45758-Z

[79] Tafiadis, D., Kosma, E.I., Chronopoulos, S.K., Voniati, L. and Ziavra, N. (2018) A Preliminary Receiver Operating Characteristic Analysis on Voice Handicap Index Results of the Greek Voice-Disordered Patients. International Journal of Otolaryngology and Head \& Neck Surgery, 7, 98-114. https://doi.org/10.4236/ijohns.2018.73013

[80] Tafiadis, D., Chronopoulos, S.K., Siafaka, V., Drosos, K., Kosma, E.I., Toki, E.I., et al. (2017) Comparison of Voice Handicap Index Scores between Female Students of Speech Therapy and Other Health Professions. Journal of Voice, 31, 583-588. https://doi.org/10.1016/j.jvoice.2017.01.013

[81] Sorensen, D. and Horii, Y. (1982) Cigarette Smoking and Voice Fundamental Frequency. Journal of Communication Disorders, 15, 135-144. https://doi.org/10.1016/0021-9924(82)90027-2

[82] Tafiadis, D., Toki, E.I., Miller, K.J. and Ziavra, N. (2017) Effects of Early Smoking Habits on Young Adult Female Voices in Greece. Journal of Voice, 31, 728-732. https://doi.org/10.1016/j.jvoice.2017.03.012

[83] Kusama, T. and Ota, K. (2002) Radiological Protection for Diagnostic Examination of Pregnant Women. Congenital Anomalies, 42, 10-14. https://doi.org/10.1111/j.1741-4520.2002.tb00848.x

[84] Schwarz, G.S. (1968) Radiation Hazards to the Human Fetus in Present-Day Society. Should a Pregnant Woman Be Subjected to a Diagnostic X-Ray Procedure? Bulletin of the New York Academy of Medicine, 44, 388-399.

[85] Haynes, B. (2002) A History of Performing Pitch: The Story of 'A'. The Scarecrow Press Inc., Lanham, Maryland, and Oxford.

[86] Geringer, J.M. (1976) Tuning Preferences in Recorded Orchestral Music. Journal of Research in Music Education, 24, 169-176. https://doi.org/10.2307\%2F3345127

[87] Barcan, L.J. (2013) Tessitura Changes in Music Theatre Repertoire for the Soprano Voice. Proceedings of 8 th International Congress of Voice Teachers, 28-42.

[88] Kelly, C.L. and Fisher, K.V. (1999) Stroboscopic and Acoustic Measures of Inspiratory Phonation. Journal of Voice, 13, 389-402. https://doi.org/10.1016/S0892-1997(99)80044-7

[89] Candemir, S. and Antani, S. (2019) A Review on Lung Boundary Detection in Chest X-Rays. International Journal of Computer Assisted Radiology and Surgery, 14, 563-576. https://doi.org/10.1007/s11548-019-01917-1 
[90] Douglas, T.S., Gresak, L.K., Koen, N., Fenton-Muir, N., van As, A.B. and Pitcher, R.D. (2012) Measurement of Prevertebral Cervical Soft Tissue Thickness on Lateral Digital Radiographs. Journal of Pediatric Orthopaedics, 32, 249-252. https://doi.org/10.1097/BPO.0b013e31824b2811

[91] Sun, A., Yeo, H.G., Kim, T.U., Hyun, J.K. and Kim, J.Y. (2014) Radiologic Assessment of Forward Head Posture and Its Relation to Myofascial Pain Syndrome. Annals of Rehabilitation Medicine, 38, 821-826. https://doi.org/10.5535/arm.2014.38.6.821

[92] Alukic, E., Skrk, D. and Mekis, N. (2018) Comparison of Anteroposterior and Posteroanterior Projection in Lumbar Spine Radiography. Radiology and Oncology, 52, 468-474. https://doi.org/10.2478/raon-2018-0021

[93] Harrison, D.E., Harrison, D.D., Cailliet, R., Troyanovich, S.J., Janik, T.J. and Holland, B. (2000) Cobb Method or Harrison Posterior Tangent Method: Which to Choose for Lateral Cervical Radiographic Analysis. Spine, 25, 2072-2078. https://doi.org/10.1097/00007632-200008150-00011

[94] Virk, J.S., Pang, J., Okhovat, S., Lingam, R.K. and Singh, A. (2012) Analysing Lateral Soft Tissue Neck Radiographs. Emergency Radiology, 19, 255-260.

https://doi.org/10.1007/s10140-012-1026-3

[95] Echternach, M., Sundberg, J., Arndt, S., Markl, M., Schumacher, M. and Richter, B. (2010) Vocal Tract in Female Registers-A Dynamic Real-Time MRI Study. Journal of Voice, 24, 133-139. https://doi.org/10.1016/j.jvoice.2008.06.004

[96] Echternach, M., Sundberg, J., Markl, M. and Richter, B. (2010) Professional Opera Tenors' Vocal Tract Configurations in Registers. Folia Phoniatrica et Logopaedica, 62, 278-287. https://doi.org/10.1159/000312668

[97] Oldendorf, W. and Oldendorf, W. (1988) Advantages and Disadvantages of MRI. In: Oldendorf, W., Ed., Basics of Magnetic Resonance Imaging, Vol. 1, Springer, Boston, 125-138. https://doi.org/10.1007/978-1-4613-2081-4 9

[98] Cleveland, T.F. (1994) A Clearer View of Singing Voice Production: 25 Years of Progress. Journal of Voice, 8, 18-23. https://doi.org/10.1016/S0892-1997(05)80315-7

[99] Murrell, G.L. (2013) Components of the Nasal Examination. Aesthetic Surgery Journal, 33, 38-42. https://doi.org/10.1177/1090820X12469626

[100] Ackermann, R. (1967) On the Problem of the Palate Form and Voice Quality. Zeitschrift für Laryngologie, Rhinologie, Otologie, 46, 280-284.

[101] Gates, L. (1998) The Singer/Actor's Voice: The Need for a Shared Pedagogy for the Successful Use of the Singing/Speaking Voice in Theatre Voice Training. Logopedics Phoniatrics Vocology, 23, 6-9. https://doi.org/10.1080/140154398433951

[102] Lammert, A., Proctor, M. and Narayanan, S. (2013) Morphological Variation in the Adult Hard Palate and Posterior Pharyngeal Wall. Journal of Speech, Language, and Hearing Research, 56, 521-530. http://doi.org/10.1044/1092-4388(2012/12-0059)

[103] Shipp, T. (1987) Vertical Laryngeal Position: Research Findings and Application for singers. Journal of Voice, 1, 217-219. https://doi.org/10.1016/S0892-1997(87)80002-4

[104] Wang, S. (1986) Singer's High Formant Associated with Different Larynx Position in Styles of Singing. Journal of the Acoustical Society of Japan, 7, 303-314. https://doi.org/10.1250/ast.7.303

[105] Sonninen, A., Hurme, P. and Laukkanen, A.M. (1999) The External Frame Function in the Control of Pitch, Register, and Singing Mode: Radiographic Observations of a Female Singer. Journal of Voice, 13, 319-340. 
https://doi.org/10.1016/S0892-1997(99)80039-3

[106] Stevens, K.A., Shimamura, R., Imagawa, H., Sakakibara, K.-I. and Tokuda, I.T. (2016) Validating Stereo-Endoscopy with a Synthetic Vocal Fold Model. Acta Acustica United with Acustica, 102, 745-751. https://doi.org/10.3813/AAA.918990

[107] Honda, K., Hirai, H., Masaki, S. and Shimada, Y. (1999) Role of Vertical Larynx Movement and Cervical Lordosis in F0 Control. Language Speech, 42, 401-411. https://doi.org/10.1177/00238309990420040301

[108] Mehta, D.D. and Hillman, R.E. (2012) Current Role of Stroboscopy in Laryngeal Imaging. Current Opinion in Otolaryngology \& Head and Neck Surgery, 20, 429-436. https://doi.org/10.1097/MOO.0b013e3283585f04

[109] DeVore, E.K., Carroll, T.L. and Shin, J.J. (2020) Is a Voice-Specific Instrument More Indicative of Stroboscopy Results than Common Clinical Queries? The Laryngoscope, 13, 992-999. https://doi.org/10.1002/lary.28207

[110] Sielska-Badurek, E.M., Jędra, K., Sobol, M., Osuch-Wójcikiewicz, E. and Niemczyk, K. (2018) Laryngeal Stroboscopy-Normative Values for Amplitude, Open Quotient, Asymmetry and Phase Difference in Young Adults. Clinical Otolaryngology, 44, 158-165. https://doi.org/10.1111/coa.13247 